\title{
Internship in Forensic Medicine \& Toxicology-A Proposed Curriculum
}

\author{
Partha S. Bhattacharyya \\ Senior Resident, Department of Forensic Medicine, Calcutta National Medical College, Kolkatta, India
}

\begin{abstract}
The controlling authority for medical education in India has finally taken the much-needed decision to increase the course duration of the subject Forensic Medicine \& Toxicology (FMT). The subject has been now included in the $3^{\text {rd }}$ Professional MBBS (Part 1), thus increasing the course duration by nearly one year. There is now also a provision for 15 days of elective internship posting in the subject. However, these 15 days of training are often not optimally utilised as there is a lack of clear-cut guidelines. The $\mathrm{MCI} / \mathrm{NMC}$ curriculum is vague and too much open for interpretation in this regard. ${ }^{1}$ So a standard curriculum that can easily be followed in all Medical Colleges of India is much necessary to ensure a uniform standard of training.

Keywords: Ethics, Forensic Internship, MBBS, Medico-Legal, Medicine \& Toxicology. Int J Eth Trauma Victimology (2021). DOI: 10.18099/ijetv.v7i02.7
\end{abstract}

\section{INTRODUCTION}

Tn the new MBBS curriculum enacted since the 2019 academic year, the subject of FMT has been given its due importance. The elective internship posting of 15 days is another step in the right direction. This posting is quite popular among the interns and almost no slots go vacant.

However, there is no uniform protocol on how to conduct the training of an Intern. Most of the faculties have never done an internship in this subject as it was not available in their time. This has led to a rather confusing situation resulting in two extreme scenarios. On one hand, the over-zealous department is trying to teach each \& every aspect of FMT to the intern, treating them like " PROXY JRs". It caused nothing but frustration to both parties.

On the other hand, the apathetic department is only concerned with the physical presence of the intern often assigning menial \& clerical jobs to him/her, thus completely devaluing the purpose of the internship.

So it is evident that a clear cut guideline and protocol is needed to address this unfortunate situation. Medico-legal litigations against doctors are on the rise and due to the COPRA $\mathrm{ACT}^{2}$, doctors have essentially become "service providers". The internship period can be utilised effectively to warn and train the budding doctors to avoid such pitfalls. It is also a golden opportunity to incite interest in the subject to choose it as a future specialization.

For this, a balanced and relevant curriculum is essential as it is useless to introduce the intern to a myriad of complex autopsies and vexing medico-legal problems. It is proven that less than $1 \%$ of a standard MBBS batch (150 students) will choose FMT as their specialization.

It is clear then that the aim of the training should be focused on the medico-legal aspects and scenarios faced by all practising doctors irrespective of speciality.
Corresponding Author: Partha S. Bhattacharyya, Senior Resident, Department of Forensic Medicine, Calcutta National Medical College, Kolkatta, India, e-mail: doctorpsbhattacharyya@gmail. com

How to cite this article: Bhattacharyya PS. Internship in Forensic Medicine \& Toxicology - A proposed. Int J Eth Trauma Victimology. 2021;7(2):35-36.

Source of support: Nil

Conflict of interest: None

Received:27/07/2021; $\quad$ Received in revised form: 14/09/2021;

Accepted:29/9/2021; $\quad$ Published:20/01/2021

The aim and objectives of the said training are multifaceted and can be broadly summarized as below:

\section{Aims and Objectives}

- Introduction: This should be done at the beginning of the training period, preferably by senior faculty members. The focus should be on the scope of the subject, the various medico-legal situation faced by practicing doctors, subtleties of Medical Ethics and Etiquette.

- Clinical Forensic Medicine: Focus should be on preparing medico-legal reports and medical certificates commonly encountered in day to day practice. Priority should be given to preparing Injury reports, sickness/fitness certificates, Death certificates and Police Intimation. How to identify and mark medico-legal cases and subsequent procedures are also covered in this section. Female interns must be sensitised to $\mathrm{POCSO}^{3}$ cases as examination by a lady doctor is mandatory in such cases.

- Autopsy: Undue emphasis must not be given on autopsy as it is unlikely that the intern will face it in future unless he/she specializes in FMT. Common cases like hanging, burn, RTA, poisoning, Myocardial infarction should 


\begin{tabular}{|c|c|c|c|}
\hline \multicolumn{4}{|c|}{ A model curriculum is provided below for ready reference } \\
\hline Day & Aims \& Objective & Focus Area & Coordinator \\
\hline 1 & Introduction & $\begin{array}{l}\text { Meet\& greet, joining formalities, the scope of FMT, Basics of } \\
\text { medical ethics \& etiquette, medical negligence }\end{array}$ & $\mathrm{HOD} /$ senior faculty \\
\hline 2 & Introduction (cont) & $\begin{array}{l}\text { Medical negligence, defence against medical negligence, } \\
\text { consent taking, duties of a doctor etc }\end{array}$ & Associate/assistant professor \\
\hline 3 & Clinical forensic medicine & $\begin{array}{l}\text { Injury report, the victim of sexual assault examination, sickness/ } \\
\text { fitness certificate }\end{array}$ & Assistant professor/SR \\
\hline 4 & Self study & NA & NA \\
\hline 5 & Autopsy & Routine cases as mentioned & Surgeon of the day \\
\hline 6 & Clinical forensic medicine & DC writing, police intimation, breaking of the bad news & SR/JR3 \\
\hline 7 & Self Study & NA & NA \\
\hline 8 & Court visit & Summon receiving, court procedures & Faculty of the day \\
\hline 9 & Autopsy & Routine cases as mentioned & Surgeon of the day \\
\hline 10 & Self Study & NA & NA \\
\hline 11 & Teaching & The pre-assigned topic for practical/demonstration class & $\mathrm{SR} / \mathrm{JR} 3$ \\
\hline 12 & Miscellaneous & Various non-academic departments work & NA \\
\hline
\end{tabular}

\#3 days have been deducted to account for Sundays/Holidays/Leaves

*Can be adjusted according to the departmental need viz ongoing exams etc

The intern will keep a record of the training in the logbook which has to be signed by the HOD before completion.

suffice. When to send a dead body for autopsy is of equal importance. Proper collection, preservation and dispatch of viscera to FSL should be covered in detail.

- Self Study: It is a bitter truth that the whole purpose of the MBBS course has been reduced to a mere passport for appearing in PG entrance exams. To deny this hard truth is similar to burying one's head in the sand. The interns should be allowed to do self-study within the department premises for at least $3 / 4$ days. He/she should be encouraged to solve the MCQs of FMT and ask for help from the faculty if needed. This will be beneficial for the intern's future and also will create an atmosphere of goodwill.

- Court visit: This is a unique part of training which is very difficult in any other department. The interns will learn how to receive a summon and accompany a faculty member for one day in court to observe the proceedings first-hand. This exposure will help him/her for any future court appearance whether as an expert witness or accused.

- Teaching: As the term "Doctor" itself means teacher, it is the role for every doctor academically inclined or not. Unfortunately during the hectic internship schedule, teaching opportunities are hard to come by. So to awaken the dormant teaching skills, the intern may be allowed to take one practical/demonstration class on a pre-assigned topic under the supervision of a junior faculty member. This will surely boost the morale and confidence of the budding doctor and may turn him/her into a skilled teacher.

- Toxicology: As the intern will gain plenty of hands-on training during medicine/casualty postings regarding poisoning cases, separate toxicological training other than what is mentioned under the "Autopsy " section is not recommended.

\section{Drawbacks}

- Difficult to follow in the departments where no medico-legal work is done. (A theoretical outlook can be given instead)

- Centres with low faculty strength will not allow proper implementation.

- Apathy from the concerned intern and lack of interest from the concerned faculties.

\section{Conclusion}

As medico-legal litigations are on the rise and the weakening of the doctor-patient relationship, a young and budding doctor must be always on guard against both legal penalties as well as physical assault. If utilized properly, the internship period in Forensic Medicine can impart crucial knowledge and skill to the would-be doctor, which will help him/her meet the everchanging and unique challenges associated with the medical profession.

\section{REFERENCES}

1. NMC Guidelines regarding internship in forensic medicine https://www.nmc.org.in/wp-content/uploads/2017/10/GME REGULATIONS-1.pdf page 90-91

2. The COPRA Act 2019 http://egazette.nic.in/WriteReadData/ 2019/210422.pdf

3. The POCSO act

4. Sharma BR, Harish D, Chavali KH. Teaching, training and practice of forensic medicine in India-An overview. Journal of Indian Academy of Forensic Medicine. 2005;27(4):247-251. 